\title{
Contribución de los viveros de empresas españolas en el mercado de trabajo
}

\section{Contribution of the nurseries of Spanish companies in the labor market}

\author{
Francisco Jesús Ferreiro Seoane ${ }^{1, \star}$, Jessica Mendoza Moheno², \\ Martín Aubert Hernández Calzada²
}

\author{
${ }^{1}$ Universidad Santiago de Compostela, España \\ ${ }^{2}$ Universidad Autónoma del Estado de Hidalgo, México
}

Recibido el 26 de noviembre del 2015; aceptado el 25 de octubre del 2016

Disponible en Internet el 11 de diciembre del 2017

\section{Resumen}

En la situación económica con altas tasas de desempleo en España, las políticas de fomento del empleo se vuelven imprescindibles. Con este artículo se pretende analizar la contribución al mercado de trabajo de los viveros de empresa en Galicia (España), siendo necesario medir la creación de empresas, empleo y tasas de supervivencia, analizando además, la eficacia de los recursos empleados por los viveros para la consecución de dichos objetivos. La eficacia de las subvenciones otorgadas a los emprendedores para la generación de puestos de trabajo fue también investigada. Los resultados muestran que los viveros son un instrumento que genera riqueza, a través de la creación de empresas y generación de empleo. Respecto a la eficacia de las subvenciones a los emprendedores para la creación de empleo, no existe una contribución al incremento de la generación de empleo en los que la reciben, aunque sin ellas habría un decremento en la creación de puestos de trabajo y un incremento en la precariedad laboral, lo que justifica su existencia.

Códigos JEL: M13, R11, O11, O43.

Palabras Clave: viveros de empresa, creación de empleo, creación de empresas, tasas de supervivencia empresarial, recursos públicos y subvenciones.

\footnotetext{
*Autor para correspondencia.

Correo electrónico: franciscojesus.ferreiro@usc.es (F.J.Ferrero Seoane)

La revisión por pares es responsabilidad de la Universidad Nacional Autónoma de México.
} 


\begin{abstract}
Within the economic situation existing in Spain with such high unemployment rates, policies to encourage employment have become indispensable. With this article, it is analysed the contribution of Galician business incubators to the labour market being necessary to measure the creation of companies and employment and the survival rates, analysing also the efficacy of the resources employed by the incubators for the achievement of those objectives. The efficacy of the grants given to the entrepreneurs for the generation of jobs has also been analysed. The results show that incubators are an instrument that generates wealth through the creation of companies and the generation of employment. Regarding the efficacy of those grants given to the entrepreneurs to create jobs, there is not a contribution to the increase of the employment in those who receive the grants even though without them there would be a decrease of the creation of jobs and an increase of labour precariousness, which justifies their existence.
\end{abstract}

JEL Classification: M13, R11, O11, O43.

Key words: Business incubators, creation of employment, creation of companies, business survival rates, public resources and grants.

\title{
Introducción
}

La crisis económica de 2008, cuyo origen radica en Estados Unidos, tuvo efectos internacionales. Así, como podemos ver en la figura 1, y de acuerdo con datos del Instituto Nacional de Estadística (INE), España pasa de tener en 2007 una tasa de paro del $8.24 \%$ a una del $24.46 \%$ en 2014, tocando máximo en 2013 (26.1\%). A pesar de que parece que está empezando a recuperarse la economía, ha supuesto en un periodo de 8 años un aumento de la tasa de paro del 197\%, lo que supone una flaqueza en un análisis de la economía española.

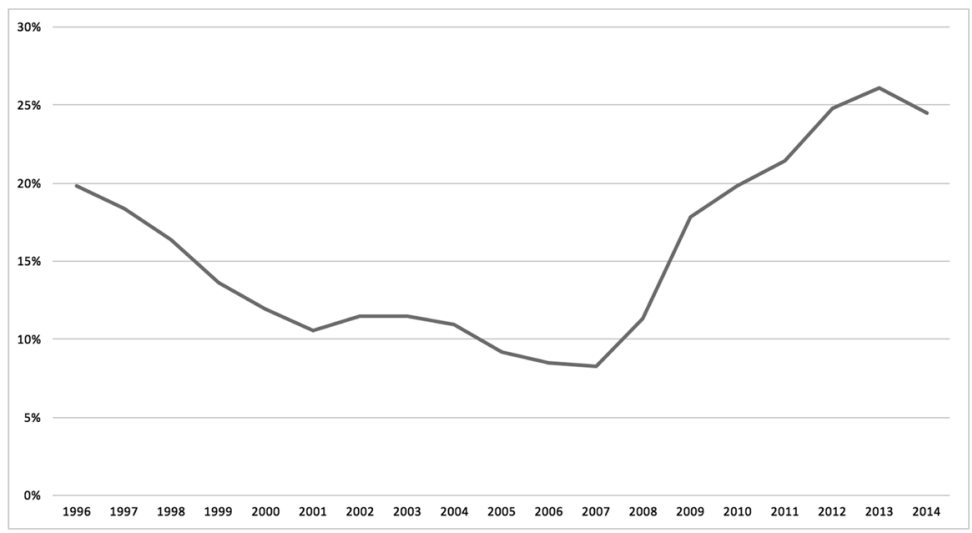

Figura 1. Evolución de la Tasa de Paro en España (1996 - 2014) Fuente: A partir de datos del INE (2015a) 
Galicia no es una excepción a la situación global que se ha experimentado en los últimos años, llegando a tener en 2014 una tasa de paro del 20.9\%, aumentando por lo tanto un $175 \%$, con máximo en 2013 (22.1\%), lo que supone una pequeña corrección en la tasa (Figura 2).

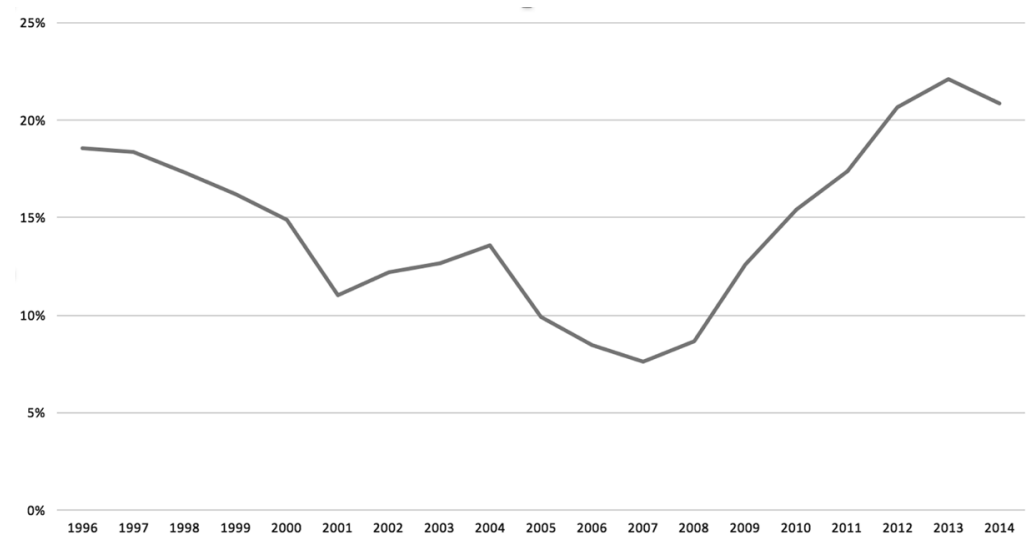

Figura 2. Evolución de la Tasa de Paro en Galicia (1996 - 2014)

Fuente: A partir de datos del INE (2015a)

Tal como se observa, a pesar de la recuperación en los últimos años, las tasas de paro siguen siendo muy elevadas, y las empresas al encontrarse en una situación de recesión económica son reacias a la contratación del personal, por lo que el emprendimiento se convierte en una alternativa muy atractiva, puesto que es una manera de intentar generar ingresos.

Existen muchas inseguridades asociadas a la figura del emprendedor, ya que la creación de un negocio tiene importantes riesgos inherentes, por lo que los sistemas de apoyo al emprendimiento se vuelven herramientas necesarias.

En el presente artículo, trataremos de justificar el uso de un sistema de apoyo concretamente, los viveros o incubadoras de empresa en la comunidad gallega, es decir, estudiaremos la contribución de los viveros de empresas al mercado de trabajo. Para ello aproximaremos el concepto de vivero de empresa mediante las contribuciones de distintos autores, y expondremos brevemente los principales objetivos. Procederemos a ver su aportación al mercado de trabajo a partir de datos obtenidos mediante encuestas realizadas a los distintos viveros gallegos, además usaremos estas encuestas para conocer la influencia de los recursos y las subvenciones en la generación y mejora de los puestos de trabajo. Por último, expondremos unas breves conclusiones donde se muestren los resultados del estudio de manera sintetizada.

\section{Revisión de la literatura}

Un vivero o incubadora puede ser concebido de diversas formas, puesto que abarca múltiples utilidades. Así, la literatura que conforma esta temática es muy amplia, ya que diversos autores han escrito sobre ella, no obstante a la hora de facilitar una definición acerca del concepto de vivero de empresa no se encuentra una universal, sino que cada autor ha aportado su grano de arena a la hora de contextualizar esta herramienta, por lo que realizaremos una revisión de algunas de las definiciones más importantes. 
Para Martínez (1987), los viveros son instalaciones donde se habilitan temporalmente espacios para el emprendimiento de actividades de I+D, habitualmente se encuentran cerca de alguna institución académica y/o centro de investigación. Siguiendo en la línea anterior se encuentra la definición ofrecida por la fundación COTEC $(1993,1998)$, considerando a los viveros como organismos potenciadores de creación de empresas, y cuyo servicio se extiende a actividades como el asesoramiento de innovaciones y formación de los emprendedores. Velasco (1995) afirma que son espacios donde se pueden realizar actividades empresariales en las primeras etapas de desarrollo productivo, puesto que se presta asistencia técnica y apoyo para la constitución de la empresa, además están financiados por el sector público o privado, ya que se trata de una política de desarrollo industrial. Por último, tenemos la definición de la European Business Incubation Centres Network (2009) que considera a los viveros como instalaciones creadas y potenciadas en un área determinada, cuyo objetivo es el desarrollo de los proyectos de las PYMES, habitualmente financiados por el sector público, puesto que se puede considerar como una contribución al desarrollo local y regional. A partir del nuevo siglo, los viveros son percibidos como ambientes institucionales que no solamente son cruciales para el crecimiento económico y prosperidad de los negocios en un sector determinado en un país, sino que además, contribuyen en forma directa e indirecta al desarrollo nacional (Perdomo Charry, Arias Pérez y Lozada Barahona, 2014).

A pesar de sólo haber analizado definiciones que muestran algunos autores en sus obras, también han aportado su definición Smilor y Gill (1986); Camacho (1998); Quintas et al. (1992); Barrow (2001); Rice (2002); Hackett y Dilts (2004); Hansson, Husted y Vestergaard (2005); NBIA (2007); UKBI (2007); Bergek y Norrman (2008); Ferreiro y Vaquero (2011), que secundan las definiciones anteriores, de modo que podemos definir un vivero como un espacio donde se establecen emprendedores en las primeras etapas de vida del proyecto para hacer uso de los servicios y funciones que ofrece el mismo. Los viveros son formas de organización, creadas frecuentemente con el apoyo de agencias para el desarrollo económico (Marlow y McAdam, 2011).

Pese a que las definiciones datan de años más tarde, la primera incubadora de empresas se creó en Batavia en 1959 (Nueva York), por lo tanto es en este momento en el que comienzan a surgir los viveros de empresas (Aerts, Matthyssens y Vandenbempt, 2007). A partir de aquí su difusión por EEUU fue veloz, concretamente sobresale el caso del parque industrial de Silicon Valley y el Standford Research Park, ambos creados por la Universidad de Standford, siendo el último un parque tecnológico cuyo propósito era el de promover la transferencia de tecnología desarrollada en el ámbito universitario hacia la creación de empresas. Sin embargo, no fue hasta veinte años después, en la década de los 70, cuando se produjo una actuación pública en esta materia gracias a programas, como EDA y NSF, con los que se buscaba el desarrollo económico y la creación de nuevas empresas; el éxito alcanzado con ellos impulsó a utilizar los viveros como instrumentos potenciadores del crecimiento económico.

En Europa, las incubadoras aparecieron principalmente en Inglaterra gracias a la British Steel Corporation y la Unión Europa, cuya actuación conjunta provocó una puesta en marcha de iniciativas que favorecían la creación y el sostenimiento de empresas, así como la generación de nuevos empleos (Rice, 2002).

A partir de la década de los 80, la Comisión Europea, junto con el apoyo de las universidades, que usaban los viveros para el desarrollo de spin-off, potenciaron la creación de centros de empresas e innovación, comercializando los productos y servicios generados por sus centros 
de investigación. Además es en este momento en el que se crea la National Business Incubator Asociation (NBIA), por lo que genera un gran potenciamiento de las incubadoras de empresas.

Desde 1990 hasta la actualidad, se han desarrollado programas comunitarios, cuya finalidad se basa en eliminar los obstáculos al desarrollo empresarial, la creación y el sostenimiento de las empresas, y apoyar la capacidad de emprender y generar nuevos empleos. Las incubadoras tienen un papel fundamental en el proceso de desarrollo económico de las localidades, ya que ponen al alcance de los emprendedores instrumentos y servicios necesarios para acelerar el crecimiento y éxito de los proyectos empresariales (Cerdán Chiscano, Jiménez Zarco y TorrentSellens, 2013).

Originalmente los viveros simplemente ofrecían un espacio físico para que las empresas pudiesen instalarse, compartir un equipamiento básico de tipo administrativo, obtener una información acerca de permisos, patentes, préstamos, recibir apoyo y asesoramiento en técnicas de dirección y marketing, disfrutar de servicios básicos a bajo coste y encontrar acceso a capital (Gatewood, Ogden y Hoy, 1985; Peterson, 1985; Allen, 1985). No obstante, con el paso del tiempo se han ido ampliando los servicios ofertados hasta el punto de convertir a los viveros en refuerzos para la creación de empresas viables, desarrollar las capacidades competitivas y aprovechar sinergias, de este modo han llegado a ser instrumentos cuya importancia es a nivel de economía en general y creación de empleo (Autio y Klofsten, 1998; Rice, 2002), en consonancia a la esencia de las incubadoras ya que con ellos se conseguía que las empresas tuviesen un gran potencial para crear empleo, revitalizar la economía local, comercializar nuevas tecnologías y fortalecer la economía regional y nacional (NBIA 1997).

Los objetivos que persiguen los viveros en general es la promoción de empresas de tal modo que logren perdurar y competir en el mercado (Hannon, 2005). Vaquero y Ferreiro (2011) consideran primordial la búsqueda del marco ideal para la creación, desarrollo y madurez de las experiencias empresariales de una zona determinada.

Existe una distinción de los objetivos perseguidos en función de si el vivero es de primera generación o de nueva economía. Así, los viveros de primera generación tienen como objetivo fomentar el surgimiento de emprendedores en zonas específicas y promover el desarrollo económico del territorio, sin embargo los viveros de nueva economía se especializan en empresas de nueva tecnología y suelen estar gestionados por el sector privado (Marimon y Alonso, 2005).

Siguiendo con lo anterior, hemos recogido un conjunto de objetivos primordiales que desarrollan los viveros de empresas, entre los que destacan fomentar la diversificación de los productos ofrecidos, mejorar las oportunidades para la creación de nuevas empresas, en especial aquellas que desarrollan su actividad en áreas innovadoras, potenciar y dinamizar el tejido empresarial y su aportación al crecimiento económico y al empleo, ofertar un entorno laboral que añada valor a las empresas que se ubican en él, tanto por la imagen de sus instalaciones, como por las prestaciones ofertadas, asesorar y formar a las empresas, incentivar el desarrollo de nuevas iniciativas empresariales, tanto de nuevas empresas como de nuevas líneas de productos de empresas ya existentes, diversificar la economía de un territorio o región e impulsar su desarrollo económico (Ferreiro, 2008).

Así, la unión entre emprendedores e inversores se realiza mediante los viveros, con respecto a la transmisión de información, nuevas ideas y proyectos. Para ello presentan una serie de servicios y funciones, los cuales se encuentran recogidos en las tablas 1 y 2. 
Tabla 1

Funciones desarrolladas por los viveros de empresas

Funciones que realizan las incubadoras de empresas

Apoyo temporal a las nuevas iniciativas empresariales, a través de la oferta a los viveristas de instalaciones y consultoría especializada.

Consolidación de nuevas empresas, minimizando los costes técnicos y económicos al inicio de la actividad.

Fortalecimiento de la capacidad emprendedora en un ambiente apropiado.

Desarrollo empresarial a través de la creación de instituciones que aglutinan intereses comunes, con el consiguiente ahorro de costes.

Mejora de las relaciones entre los centros de investigación públicos y privados y entre las propias empresas.

Favorecer el desarrollo de proyectos empresariales.

Aumento de la tasa de éxito de las pequeñas y medianas empresas, especialmente cuando son más vulnerables.

Contribución a la generación de empleo.

Formación a los emprendedores para mejorar sus capacidades y mejorar su competitividad

Contribuyen al desarrollo local y regional

Fuente: Vaquero y Ferreiro (2010a); Martínez (1987); COTEC (1998); European Business Incubation Centres Network (2009); NBIA (2007); UKBI (2007).

Tabla 2

Servicios ofertados por los viveros

\begin{tabular}{|c|c|}
\hline Servicios ofertados & Especificaciones \\
\hline $\begin{array}{l}\text { Servicios logísticos } \\
\text { y administrativos }\end{array}$ & $\begin{array}{l}\text { - Naves, oficinas o módulos polivalentes (con una superficie adaptada a las } \\
\text { necesidades de los viveristas y a precios más reducidos que los de mercado). } \\
\text { - Salas de reuniones y espacios comunes. } \\
\text { - Servicios compartidos de fotocopiadora, fax, escáner y conexión a internet. } \\
\text { - Estos servicios son ofertados por un tiempo limitado }\end{array}$ \\
\hline Consultoría empresarial & $\begin{array}{l}\text { Información y asesoramiento sobre la mejor forma jurídica de la empresa, } \\
\text { ayudas y subvenciones a las que puede acogerse y otros servicios de } \\
\text { asesoramiento y gestión empresarial. }\end{array}$ \\
\hline Formación empresarial & $\begin{array}{l}\text { - Acciones formativas a los empleados. } \\
\text { - Seminarios monográficos y encuentros sectoriales. } \\
\text { - Formación a los emprendedores para mejorar sus capacidades y mejorar su } \\
\text { competitividad }\end{array}$ \\
\hline
\end{tabular}

Fuente: Vaquero y Ferreiro (2010b), COTEC (1998); NBIA (2007); UKBI (2007).

\section{Metodología}

El objetivo del presente artículo es analizar en qué medida los viveros de empresas contribuyen al desarrollo económico, para ello se deben cuantificar los fines de estos centros, como son el número de empresas generadas, los puestos de trabajo creados y tasa de abandono de las empresas. Y dado que en España existe un gran problema de desempleo, nos hemos centrado en el impacto que tienen los viveros en la creación de empleo en Galicia y sus comarcas. Pero, los centros de iniciativa empresarial consumen recursos, por lo que se analizó 
la relación de eficacia entre los recursos de los viveros (que en gran medida dependen del sector público) y la generación de empresas, y especialmente empleo. El segundo objetivo parte del planteamiento de que casi el $81 \%$ de las empresas recibe subvenciones para la creación de puestos de trabajo, cuestionándonos si éstas crean más empleo que las que no lo reciben. Por tanto, el objetivo no es sólo analizar la contribución de los viveros de empresas, sino que se pretende analizar la eficacia de los recursos empleados para la creación de empleo.

La metodología está basada en cuantificar la creación de empresas, empleo y su supervivencia, y para ello, se han empleado encuestas realizadas a todos los viveros de Galicia. Se ha analizado el impacto que tienen en el territorio, ya que son políticas de desarrollo regional. Para analizar la eficacia de los recursos de los viveros y el grado de consecución de los objetivos, a nivel estadístico, se ha analizado la correlación de Pearson, y su significatividad, junto con regresiones, entre los recursos empleados por los viveros y la creación de empresa y empleo. Para analizar la eficacia de las subvenciones a los emprendedores para la creación de empleo, se ha utilizado el Análisis de Varianza Unifactorial, a través del estadístico F, y con la prueba de Levene que informa si el estadístico cumple el supuesto de varianzas iguales. Así, a través de muestras independientes se comparan la creación de puestos de trabajo por actividad empresarial, de los emprendedores de los viveros de empresa que han recibido subvenciones para la creación de empleo con los que no han recibido subvenciones.

Esta es una metodología distinta a la empleada en Ferreiro et al (2015), donde a través de un modelo econométrico se analizaron los recursos totales empleados en los viveros de empresas, que sirven para financiar espacio y profesionales para atender a los emprendedores que crean empresas, generan puestos de trabajo y pagan impuestos. En Ferreiro y Rodriguez (2015), a través de otro modelo de ecuaciones estructurales se analizó la influencia de los recursos públicos, dado la dependencia de los viveros de empresas de las ayudas públicos. En Ferreiro y Camino (2016), a través del método Fiscal se analiza si lo invertido por el sector público en este tipo de instalaciones se recupera vía recaudación de impuestos y si es rentable hacerlo. En este artículo el objetivo y la metodología está más orientada a analizar el impacto en la creación de empleo y si se cumple dicho objetivo a través de los viveros de empresas.

Toda metodología tiene limitaciones metodológicas. No todas las empresas, ni todos los puestos de trabajo generados serían creados gracias a los viveros de empresas, ya que algunas iniciativas empresariales se hubieran desarrollado y sobrevivido sin estar en la incubadora. Teniendo en cuenta que la tasa de mortalidad hasta el cuarto año de las empresas en España es del 46.3\% (INE, 2015b), lo cual nos indica que el 53.7\% de las empresas hubiesen sobrevivido igual aunque no estuvieran en el vivero. Dado que la tasa de supervivencia de las empresas ubicadas en los viveros gallegos es del $90.8 \%$ al cuarto año, se puede considerar que el $37.1^{3 \%}$ de las empresas que salen de los viveros está directamente relacionado con este tipo de instrumento de creación de empresas. Este hecho se ha tenido en cuenta a la hora de hacer análisis tales como el impacto de empresas y empleo generados, o para calcular el impacto de desempleo por zona o comarca. Ahora bien, a la hora de analizar la relación y la eficacia de los recursos empleados por los viveros de empresas, entendemos que se deben imputar tanto el total de recursos consumidos como su contribución total, para que exista una correlación lógica entre recursos consumidos y contribuciones aportadas. Por otro lado, cuando los gobiernos otorgan una subvención para la creación de empleo en general, no lo hacen en función de que

\footnotetext{
${ }^{3}$ Es la diferencia entre la tasa de supervivencia de las empresas en los viveros de empresas y la de las empresas en general.
} 
una empresa esté en un vivero o ubicada en otro lugar, por ello, para analizar la rentabilidad de las subvenciones a la creación de empleo, no podemos centrarnos sólo en las iniciativas empresariales que hipotéticamente sobreviven gracias a los viveros de empresas, pues nuestro tamaño muestral y objeto de análisis son todas las actividades empresariales ubicadas en la incubadoras de empresas.

Existen otras limitaciones, pues la captura de información ha sido en base a lo declarado en las encuestas contestadas por los emprendedores $(56.1 \%)$ y por los viveros de empresas (100\%), (Ferreiro et al, 2015)al no disponer, al menos en Galicia, de ninguna fuente oficial ni asociación que indique algo tan básico como el número de viveros totales de Galicia y su ubicación, lo que ha supuesto un gran esfuerzo para conseguir toda la información necesaria a la hora de testar este modelo, si bien ahora constituye un punto fuerte el disponer de esta información relativa a los viveros. Otra restricción es que la metodología se centra en recursos consumidos frente a tres aportaciones (empresas creadas, empleo y tasas de supervivencia), pero existen otras variables que influyen en la contribución de los viveros, no ponderadas, como la difusión de la cultura emprendedora, el asesoramiento a empresas que no demandaron espacios en los viveros, etc. Otra limitación es la temporal, se midió para el período 2009-2014, lo que no significa que en otros períodos los resultados puedan ser diferentes. También se debe resaltar que el análisis se realiza en España, un país muy sensible al empleo por sus altas tasas de desempleo.

\section{Contribución al mercado de trabajo}

La situación económica actual, aparejada con altas tasas de desempleo en España, ha llevado a la búsqueda de nuevas alternativas para la generación de empleo, teniendo los viveros de empresas como objetivos: la creación de empresas; la generación de empleo; la cohesión social, evitando la deslocalización económica; el crecimiento y desarrollo económico, estimulando el impulso económico en la zona donde se desarrollan, posibilitando la generación de riqueza; el aumento de las capacidades de los emprendedores; el desarrollo de redes de trabajo, potenciándose el trabajo en red y la colaboración empresarial; el mejoramiento de las tasas de supervivencia de las empresas; y el aumento de la recaudación fiscal (Autio y Klofsten, 1998; Colombo y Delmastro, 2001; Lalkala, 2002; Rice, 2002; Totterman y Sten, 2005; Hughes, Ireland y Morgan, 2007; NBIA 2007; McAdam y McAdam, 2008; Uribe y De Pablo, 2009; Scillitoe y Chakrabarti, 2010; Thierstein y Wilhem, 2011; Vaquero y Ferreiro, 2011, 2014; Bollingtoft, 2012; Ferreiro 2014).

Lewis (2001) confirma lo anterior exponiendo que los viveros son una herramienta de promoción para la creación de nuevas empresas. Esta afirmación se ve reforzada por la existencia de 900 incubadoras que crearon más de 19,000 empresas y por ende, 245,000 puestos de trabajo en el año 2002 en Estados Unidos (Scaramutzzi, 2002). En el caso europeo, Alemania es el país con mayor número de viveros, seguido de Francia y Reino Unido (Fernández, Blanco, Alonso, Santos, González-Blanch, Romero y González, 2011). España no resulta ser una excepción al fenómeno de las incubadoras, ya que se estima que existen alrededor de 300, siendo Cataluña la comunidad autónoma que cuenta con mayor porcentaje de viveros, seguida por Andalucía, Madrid y Valencia (Vaquero y Ferreiro, 2014). Sin embargo, a pesar de no estar dentro de los cuatro primeros puestos, Galicia contaba en 2014 con 22 viveros de empresas con una fuerte concentración territorial, Ourense cuenta con el mayor porcentaje de viveros de toda la comunidad, seguido de A Coruña, Santiago de Compostela y Lugo. 
Como podemos ver en la tabla 3, los viveros contribuyeron en 2014 a la generación de empleo, mediante la creación de 1,150 empresas y 3,498 puestos de trabajo, suponiendo un aumento del $3.06 \%$ frente al año anterior en las incubadoras de empresas. Tal como vimos anteriormente que el $37.1 \%$ de la actividad está directamente relacionado con los viveros de empresas, estos ascenderían a 427 empresas y 1,298 puestos de trabajos.

Tabla 3

Indicadores en materia de creación de empresas, empleo y tasas de abandono (2014)

\begin{tabular}{|c|c|c|c|}
\hline Vivero & $\begin{array}{l}\text { Empresas } \\
\text { generadas }\end{array}$ & $\begin{array}{l}\text { Empleo } \\
\text { generado }\end{array}$ & $\begin{array}{l}\text { Tasa de abandono } \\
\text { (acumulada) }\end{array}$ \\
\hline Cámara de Comercio de A Coruña & 20 & 83 & $7.3 \%$ \\
\hline Cámara de Comercio de Ferrol & 26 & 51 & $12.1 \%$ \\
\hline Cámara de Comercio de Lugo & 13 & 15 & $8.4 \%$ \\
\hline Cámara de Comercio de Ourense- Fernando Fontán & 36 & 69 & $15.4 \%$ \\
\hline Cámara de Comercio de Pontevedra- Eladio Portela & 18 & 22 & $7.9 \%$ \\
\hline Cámara de Comercio de Santiago de Compostela & 75 & 128 & $9.8 \%$ \\
\hline Cámara de Comercio de Vigo & 79 & 187 & $11.9 \%$ \\
\hline Cámara de Comercio de Vilagarcía de Arousa & 20 & 43 & $13.0 \%$ \\
\hline $\begin{array}{l}\text { Centro de Experimentación y Desarrollo Empresarial- Fundación } \\
\text { Empresa Universidad Gallega (CEDE-FEUGA) }\end{array}$ & 54 & 107 & $14.3 \%$ \\
\hline $\begin{array}{l}\text { Centro de Empresas e Innovación (CEI NODUS). Ayuntamiento } \\
\text { de Lugo }\end{array}$ & 33 & 94 & $12.6 \%$ \\
\hline $\begin{array}{l}\text { Centro de Iniciativas Empresariales (CIE) A Granxa- Fernando } \\
\text { Conde Montero-Ríos Vigo }\end{array}$ & 94 & 252 & $10.9 \%$ \\
\hline CIE de Terras do Avia O Ribeiro & 7 & 23 & $6.0 \%$ \\
\hline CIE del ayuntamiento de Coles Ourense & 23 & 54 & $6.0 \%$ \\
\hline CIE del ayuntamiento de Ourense & 14 & 30 & $6.9 \%$ \\
\hline CIE Mans Coruña & 51 & 160 & $7.9 \%$ \\
\hline CIE Seara Eume & 3 & 8 & $0 \%$ \\
\hline CIE Tecnópole Ourense & 343 & 1.098 & $9.9 \%$ \\
\hline Centro Municipal de Empresas (CME Iglexario A) Coruña & 20 & 43 & $5.5 \%$ \\
\hline $\begin{array}{l}\text { Fundación de la Confederación de Empresarios de Lugo- } \\
\text { Iniciativas por Lugo }\end{array}$ & 67 & 475 & $6.7 \%$ \\
\hline $\begin{array}{l}\text { Incubadora de Empresas de la Confederación de Empresarios de } \\
\text { Ferrol }\end{array}$ & 9 & 22 & $7.5 \%$ \\
\hline OTRI-Universidad de A Coruña & 31 & 93 & $12.9 \%$ \\
\hline UNINOVA-Universidad de Santiago de Compostela & 114 & 441 & $8.5 \%$ \\
\hline Total /promedio (tasas) & 1.150 & 3.498 & $9.2 \%$ \\
\hline Total /promedio (tasas) gracias a los viveros de empresas & 427 & 1.298 & $9.2 \%$ \\
\hline
\end{tabular}


Las incubadoras de empresas que más han contribuido a la creación de empleo son el de Tecnópole $(1,098)$, que es tecnológico; la Fundación de la Confederación de Empresarios de Lugo-Iniciativas por Lugo (475); UNINOVA-USC (441), que también es tecnológico vinculado a la Universidad de Santiago de Compostela; además CIE A Granxa (252), Cámara de Comercio de Vigo (187) y CIE Mans (160) también presentan un elevado número de puestos de trabajo creados. No obstante, a pesar de que éstos son los líderes, todos los viveros contribuyen al mercado de trabajo con puestos que generan empleo.

Tabla 4

Puestos de trabajo creados a través de los viveros de empresas, por comarcas (2014)

\begin{tabular}{|c|c|c|c|c|}
\hline Comarca & $\begin{array}{l}\mathrm{N}^{\mathrm{o}} \text { Puestos de } \\
\text { trabajos Creados } \\
\text { por los viveros }\end{array}$ & $\%$ s/total viveros & Desempleo Comarcal & $\begin{array}{l}\text { Empleo viveros } \\
\text { /desempleo } \\
\text { comarca) }\end{array}$ \\
\hline Ourense & 1251 & $35.76 \%$ & 13210 & $9.47 \%$ \\
\hline Lugo & 584 & $16.70 \%$ & 10352 & $5.64 \%$ \\
\hline Santiago & 676 & $19.33 \%$ & 14138 & $4.78 \%$ \\
\hline Vigo & 439 & $12.55 \%$ & 46848 & $0.94 \%$ \\
\hline Bergantiños & 83 & $2.37 \%$ & 7304 & $1.14 \%$ \\
\hline O Ribeiro & 23 & $0.66 \%$ & 1351 & $1.70 \%$ \\
\hline A Coruña & 296 & $8.46 \%$ & 35386 & $0.84 \%$ \\
\hline Ferrol & 73 & $2.09 \%$ & 16237 & $0.45 \%$ \\
\hline O Salnés & 43 & $1.23 \%$ & 12342 & $0.35 \%$ \\
\hline Eume & 8 & $0.23 \%$ & 2116 & $0.38 \%$ \\
\hline Pontevedra & 22 & $0.63 \%$ & 12631 & $0.17 \%$ \\
\hline Total & 3498 & $100 \%$ & 171915 & $2.03 \%$ \\
\hline Total incremento ${ }^{5}$ neto & 1298 & $37.11 \%$ & & $0.76 \%$ \\
\hline $\begin{array}{l}\text { Total de las tres primeras } \\
\text { comarcas }\end{array}$ & 2511 & $71.78 \%$ & & $6.66 \%$ \\
\hline $\begin{array}{l}\text { Total incremento }{ }^{6} \text { neto de } \\
\text { las tres primeras comarcas }\end{array}$ & 931 & $26.62 \%$ & & $2.47 \%$ \\
\hline
\end{tabular}

En la tabla 4 se puede observar una comparativa de los puestos de trabajos creados en total y directamente, en los viveros de empresas gallegos, el paro por zonas y una relación entre el empleo generado y el desempleo comarcal. Ahora bien estos datos hay que interpretarlos con cautela, ya que no podemos afirmar que todos los empleos generados sean incrementos netos, al desconocer la situación previa de los emprendedores y de los contratados por ellos. A pesar de esta limitación, parece lógico pensar que sin los viveros de empresas el número de desempleados aumentaría en un $2.03 \%$ respecto a los desempleados existentes, fruto de los 3,498 puestos de trabajo generados en los viveros. Pero si consideramos el empleo creado directamente gracias a la acción de los viveros, el impacto de disminución del número de desempleados sería del $0.76 \%$, lo que significan 1,298 empleos. Si nos centramos en las tres 
primeras zonas geográficas donde operan los viveros, los puestos de trabajo creados ascienden a 2,511 que supone no incrementar el número de desempleos respecto al total existente en un $6.66 \%$, la cual imputable directamente a los viveros de empresas bajarían a 931 puestos de trabajo y un porcentaje del $2.47 \%$.

Siguiendo con el análisis de la creación de puestos de trabajo, también resulta interesante estudiar la relación existente entre las empresas y la creación de empleo, de tal modo que en la tabla 5 podemos observar que el coeficiente de correlación de Pearson entre la creación de empresas y la generación de empleo es de 0.966 (2009) y 0.959 (2014), en ambos casos con una significatividad muy alta.

Tabla 5

Correlaciones entre creación de empresas y generación de empleo para datos acumulados 2009 y 2014

\begin{tabular}{llrr}
\hline & & $\begin{array}{l}\text { Empleo } \\
\text { Acumulado 2009 }\end{array}$ & \multicolumn{1}{c}{$\begin{array}{c}\text { Empleo } \\
\text { Acumulado 2014 }\end{array}$} \\
\hline $\begin{array}{l}\text { Empresas } \\
\text { acumulado }\end{array}$ & Correlación de Pearson & $0.966^{* * * *}$ & $0.959^{* *}$ \\
$2009 / 2014$ & Sig. (bilateral) & 0.000 & 0.000 \\
& $\mathrm{~N}$ & 21.000 & 22.000 \\
\hline
\end{tabular}

*** La correlación es significativa al nivel 0.001 (bilateral).

\section{Influencia de los recursos de los viveros en la creación de empleo}

Toda organización que desempeñe alguna actividad necesita recursos económicos para llevarla a cabo, por ello se analiza a continuación la influencia que provocan los recursos en la creación de empleo en los viveros. Al realizar un análisis de regresión entre los recursos de los viveros y la creación de empleo vemos un coeficiente de correlación de Pearson de 0.627, el cual al elevarse al cuadrado resulta una $\mathrm{R}^{2}=39.3 \%$, lo que hace que los recursos de los viveros de 2009 expliquen en dicho porcentaje la creación de empleo y siendo significativa la regresión, tal como se observa en la tabla 6.

Tabla 6

Regresión entre los recursos de los viveros gallegos y la creación de empleo con datos acumulados al 2009

\begin{tabular}{lllll}
\hline \multicolumn{2}{l}{ Resumen del modelo } & & \\
\hline Modelo & $\mathrm{R}$ & R cuadrado & R cuadrado corregida & Error típico de la estimación \\
1 & $0.627^{\mathrm{a}}$ & 0.393 & 0.361 & 29.56397 \\
\hline
\end{tabular}

a. Variables predictoras: (Constante), Recursos09

\footnotetext{
${ }^{5}$ Sería descontando como creación de empleo, aquellos que manifestaron que crearían igual su empresa y generación de puestos de trabajo fuera del vivero de empresa

${ }^{6}$ Sería descontando como creación de empleo, aquellos que manifestaron que crearían igual su empresa y generación de puestos de trabajo fuera del vivero de empresa pero referidas a las tres primeras comarcas
} 
Tabla 6 (Continuación)

Regresión entre los recursos de los viveros gallegos y la creación de empleo con datos acumulados al 2009

\begin{tabular}{|c|c|c|c|c|c|c|}
\hline \multicolumn{7}{|c|}{ Coeficientes ${ }^{\mathrm{a}}$} \\
\hline \multirow{2}{*}{\multicolumn{2}{|c|}{$\begin{array}{l}\text { Modelo } \\
\text { B }\end{array}$}} & \multicolumn{2}{|c|}{ Coeficientes no estandarizados } & \multirow[t]{3}{*}{ Coeficientes tipificados } & \multirow{2}{*}{$\mathrm{t}$} & \multirow{2}{*}{ Sig. } \\
\hline & & Error típico & Beta & & & \\
\hline \multirow{2}{*}{1} & (Constante) & 10.438 & 10.328 & & 1.011 & 0.325 \\
\hline & Recursos09 & 0.000 & 0.000 & 0.627 & 3.506 & 0.002 \\
\hline
\end{tabular}

a. Variable dependiente: Empleo 09

No obstante en el caso del año 2014, como se indica la tabla 7, los recursos de los viveros pasan a explicar el $32.7 \%$ de la creación de empleo, siendo este dato significativo estadísticamente.

Tabla 7

Regresión entre los recursos de los viveros gallegos y la creación de empleo con datos acumulados al 2014

\begin{tabular}{lrrrr}
\hline Modelo & $\mathrm{R}$ & R cuadrado & $\begin{array}{l}\text { R cuadrado } \\
\text { corregida }\end{array}$ & Error típ. de la estimación \\
\hline 1 & $.572^{\mathrm{a}}$ & .327 & .293 & 206.09369
\end{tabular}

Variables predictoras: (Constante), Recursos_viveros

Coeficientes $^{\mathrm{a}}$

\begin{tabular}{llccccc}
\hline Modelo & Coeficientes no estandarizados & $\begin{array}{l}\text { Coeficientes } \\
\text { tipificados }\end{array}$ & t & Sig. \\
\hline & B & Error típ. & Beta & & & \\
\hline 1 & $\begin{array}{l}\text { (Constante }) \\
\text { Recursos_viveros }\end{array}$ & -14.688 & 70.946 & & -.207 & .838 \\
\end{tabular}

a. Variable dependiente: Empleo_viveros

\section{Relevancia de las subvenciones en la generación de puestos de trabajo}

Existen diversas formas de obtener financiación, una de ellas son las subvenciones recibidas a través del sector público a fondo perdido, cuyo objetivo es la activación de la economía y concretamente las que se otorgan para la creación de empleo. Así el porcentaje de viveros de empresas cuya financiación incluye subvenciones es del $80.56 \%$.

Hay autores que piensan que este hecho no es positivo, sino todo lo contrario, así Urbano y Vecina (2001) afirman que estas ayudas dependen excesivamente de los ciclos políticos, del mismo modo Nueno (2009) afirma que la creación de empleo y competitividad no dependen de las subvenciones sino de la productividad, puesto que un proyecto emprendedor debe ser viable desde un punto de vista técnico, económico y financiero, de modo que las subvenciones son ayudas pero no son un factor clave.

Para ver la influencia de las subvenciones, se aplicó el Análisis de Varianza Unifactorial, comparando la creación de puestos de trabajo entre emprendedores que sí recibieron subvención y aquellas que no, de modo que se puede apreciar en la tabla 8 , que el promedio de empleo entre los que recibieron subvención (3.81 puestos de trabajo) y los que no (3.82) es prácticamente el mismo, siendo significativo estadísticamente $(\mathrm{t}=0.011 ; \mathrm{p}=0.991)$. 
Con los resultados exhibidos, los emprendedores que han recibido subvenciones no generan más empleo que los que no las han recibido, coincidiendo con las ideas de algunos autores que hemos mencionado.

Tabla 8

Comparación de puestos de trabajo creados entre emprendedores que recibieron subvención y los que no recibieron subvención (2009)

\begin{tabular}{llllll}
\hline \multicolumn{6}{l}{ Grupos Estadísticos } \\
\hline \multirow{4}{*}{ Empleo } & Subvención & $\mathrm{N}$ & Media & Desviación Estándar & Media error estándar \\
& No recibida & 28 & 3.8214 & 5.93828 & 1.12223 \\
& Si recibida & 116 & 3.8103 & 4.28529 & 0.39788 \\
\hline
\end{tabular}

\begin{tabular}{|c|c|c|c|c|c|c|c|c|c|c|}
\hline \multicolumn{11}{|c|}{ Prueba de muestras independientes } \\
\hline & & \multicolumn{2}{|c|}{$\begin{array}{l}\text { Prueba de } \\
\text { Levene para } \\
\text { la igualdad } \\
\text { de varianzas }\end{array}$} & \multicolumn{7}{|c|}{ Prueba T para la igualdad de medias } \\
\hline & & \multirow[t]{2}{*}{$\mathrm{F}$} & \multirow[t]{2}{*}{ Sig. } & \multirow[t]{2}{*}{$\mathrm{t}$} & \multirow[t]{2}{*}{ gl } & \multirow[t]{2}{*}{$\begin{array}{l}\text { Sig. } \\
\text { (bilateral) }\end{array}$} & \multirow[t]{2}{*}{$\begin{array}{l}\text { Diferencia } \\
\text { de medias }\end{array}$} & \multirow{2}{*}{$\begin{array}{l}\text { Error } \\
\text { típico } \\
\text { de la } \\
\text { diferencia }\end{array}$} & \multicolumn{2}{|c|}{$\begin{array}{l}95 \% \text { Confidence } \\
\text { Interval of the } \\
\text { Difference }\end{array}$} \\
\hline & & & & & & & & & Inferior & Superior \\
\hline \multirow{2}{*}{$\frac{8}{\stackrel{0}{Z}}$} & $\begin{array}{l}\text { Se han } \\
\text { asumido } \\
\text { varianzas } \\
\text { iguales }\end{array}$ & 0.012 & 0.913 & 0.011 & 142 & 0.991 & 0.01108 & 0.97807 & -1.92237 & 1.94454 \\
\hline & $\begin{array}{l}\text { No se han } \\
\text { asumido } \\
\text { varianzas } \\
\text { iguales }\end{array}$ & & & 0.009 & 34.08 & 0.993 & 0.01108 & 1.19068 & -2.40843 & 2.43060 \\
\hline
\end{tabular}

No obstante se debe ser prudente con la comparativa pues la conclusión podría ser que dado que los emprendedores que no reciben subvención crean el mismo empleo que los que la reciben, no serían necesarias. No se puede olvidar que aquellos que no la percibieron representan el $19.44 \%$, de tal manera que habría que analizar el impacto que tendría entre el colectivo del $80.56 \%$, que sí la percibieron. El $90.7 \%$ de los que recibieron ayudas para la contratación de personal, manifestaron que no hubieran creado empleo sin dichas ayudas. Por otro lado, las subvenciones obligan a unas condiciones, que respeten la categoría profesional y se mantengan los puestos de trabajo 3 años con contratos indefinidos,

Concluyendo este apartado, es un hecho objetivo que en Galicia los emprendedores de los viveros de empresas que no han recibido ayudas para la contratación han generado la misma tasa de empleo por actividad; que los que perciben ayudas representan el $81.1 \%$ y que mayoritariamente manifiestan que no hubieran creado empleo sin dichas ayudas. 


\section{Conclusiones}

La principal conclusión que podemos extraer trata sobre la relevancia de los viveros de empresas como mecanismos de generación de empleo en la actual situación de crisis en la que nos encontramos, puesto que con ellos se crearon en 2014, en la Comunidad Autónoma de Galicia, (España), 1,150 empresas, 3,498 puestos de trabajo y una tasa de abandono de 9.2\% cuando la media fuera de los viveros en España es del 46.3\%. Incluso contabilizando exclusivamente las aportaciones de las empresas que manifestaron que fue gracias a los viveros, los datos serían de 427 empresas, 1,298 empleos.

Dentro de los viveros más generadores de empleo están los denominados tecnológicos, Tecnópole y UNINOVA - USC, pero no se puede concluir que éstos contribuyan más que los generalistas gestionados por las confederaciones de empresarios o Cámaras de Comercio.

Otra conclusión, es que el empleo generado en los viveros de empresas, aumentaría el número de desempleados en un $2.03 \%$ en las comarcas donde existen viveros, y del 0.76 si consideramos sólo los que se crean exclusivamente por la acción del vivero. En las principales áreas donde hay viveros, estos ratios supondrían en torno al $6.66 \%$ y $2.47 \%$ respectivamente.

La correlación de un $96.6 \%$ entre la creación de empresas y empleo, evidencia la importancia de las políticas de fomento de empresas para combatir el desempleo.

Una pregunta crucial planteada es la eficacia de los recursos de los viveros de empresa empleados en la creación de empleo, apreciándose que las regresiones entre empleo y recursos tanto para el año 2009 y 2014, son positiva y significativas. Por tanto se puede concluir que los recursos de los viveros de empresas son un factor relevante para la generación de empleo de los viveros, puesto que los viveros con mayores volúmenes de recurso fueron los generadores de mayores volúmenes de empleo.

Por otro lado, se aprecia en la tabla 8, que las empresas beneficiarias de subvenciones públicas tienen de promedio de empleo el mismo ratio que los que no han recibido ayuda pública alguna. No obstante, no se puede afirmar categóricamente que son innecesarias, puesto que el $90.9 \%$ de los que las reciben manifestaron que no crearían empleo sin estas ayudas. Por otro lado la percepción de la subvención obliga a unos requisitos, tales como mantener el empleo tres años y cotizar acorde a la formación del profesional contratado.

Entre las principales limitaciones de la investigación debemos indicar la ausencia de datos oficiales específicos para estos centros de iniciativas empresariales. Así mismo, existe una limitación temporal, ya que el trabajo está referido para un período de crisis, lo cual puede cambiar sustancialmente si se estudian los efectos de los viveros en otro contexto económico. Este trabajo de investigación se basa en datos cuantitativos, por lo que las conclusiones están condicionadas a la información disponible.

Por último, como futuras líneas de investigación se recomienda hacer estudios dirigidos a la medición de la eficacia de los viveros de empresas y de las subvenciones en otras regiones del mundo y comparar dichos resultados. También sería interesante en unos años volver hacerlo en Galicia para ver si se obtienen resultados similares a los obtenidos en la presente investigación.

\section{Referencias}

Aerts, K., Matthyssens, P. \& Vandenbempt, K. (2007). Critical role and screening practices of European business incubators. Technovation, 27(5), 254-267. doi.org/10.1016/j.technovation.2006.12.002 
Allen, D. (1985). An entrepreneurial marriage: business incubators. V Congreso Anual Balson Collage Entrepreneurship Research. Wellesley, Maryland.

Autio, E. \& Klofsten, M. (1998). A comparative study of two European business incubators. Journal of Small Business Management, 36(1), 30-43.

Barrow, C. (2001). Incubator: A realist's guide to the world's new business accelerators. West Sussex, UK: John Wiley \& Sons Ltd.

Bergek, A. \& Norman, C. (2008). Incubator best practice: A framework. Tecnnovation. https://doi.org/10.1016/j.technovation.2007.07.008

Bollingtoft, A. (2012). The bottom-up business incubator: Levergae to nerworking and cooperativon practices in a self-generated, entrepreneurial-enabled environment. Technovation, 32 (5), 304-315 doi.org/10.1016/j.technovation.2007.07.008

Camacho, J. (1998). Incubadoras o viveros de empresas de base tecnológica: La reciente experiencia europea como referencia para las actuales y futuras iniciativas latinoamericanas. XII Congreso Latinoamericano sobre espíritu empresarial. Costa Rica.

Cerdán Chiscano, M., Jiménez Zarco. A.I. \& Torrent-Sellens, J. (2013). Valorando los programas de apoyo al emprendedor en las incubadoras de empresas en Cataluña. Revista Venezolana de Gerencia, 18(63), 408-433.

Colombo, M. G. \& Delmastro, M. (2002). How effective are technology incubators?: Evidence from Italy. Research Policy, 31(7), 1103-1122. https://doi.org/10.1016/s0048-7333(01)00178-0

COTEC (1993). Conceptos básicos de referencia para el estudio de la innovación tecnológica. Madrid: Fundación COTEC.

COTEC (1998). Libro Blanco. El sistema español de innovación. Diagnóstico y recomendaciones. Madrid: Fundación COTEC.

Fernández, P., Blanco, F.J., Alonso, M.A., Santos, M., González-Blanch, Romero, A. \& González, L. (2011). El papel de los viveros de empresas en la creación de empleo. Universidad Rey Juan Carlos. Disponible en: http://www. madrid.org/edupubli/cgi-bin/WPUB_BD.exe?ACCION=RecogerPDF\&CDDEPTNO=09\&CDTEXP=PU\&CDAEXP $=2012 \& C D N E X P=51 \& C D D I G I T O=5 \& C D E S T A D O=3 \& N M O R D E N=2$

Ferreiro, F. (2008). Los viveros de empresas de Galicia: Una manera de emprender. XXII Congreso AEDEM. Salamanca.

Ferreiro, F. (2014). Los viveros de empresas en Galicia: Una estrategia generadora de riqueza. Tesis doctoral, Universidad de A Coruña.

Ferreiro, F., Del Campo M., Camino, M. (2015). Analysis of business incubators in Galicia through the «Integral Model of economic profitability». Investigaciones Regionales - Journal of Regional Research, (33), 7-31.

Ferreiro, F. \& Rodriguez, G (2015). Análisis de la eficacia de los recursos empleados en los viveros de empresas gallegas. Información Comercial Española. Ministerio de Economía y Competitividad. (90), 257-276.

Ferreiro, F. \& Camino, M. (2016). Análisis cuantitativo de los centros de iniciativas empresariales medido a través del método de la balanza fiscal: el caso gallego. Revista Galega de Economía. 25 (1), 61-75.

Gatewood, B; Ogden, L. \& Hoy, F. (1985). Incubator centers: Where they are and where are they going. V Congreso Anual Babson College Enterpreneurship Research. Maryland: Wellesley.

Hackett, S. y Dilts, D. (2007). Inside the black box of business incubation: Study B-scale assessment, model refinement and incubation outcomes. Journal of Technology Tansfer, 33(5), 439-471. https://doi.org/10.1007/s10961-0079056-9

Hansson, F., Husted, K. \& Vestergaard, J. (2005). Second generation science parks: from structural jockeys to social capital catalysts of the knowledge society. Technovarion, 25(9), 1039-1049. https://doi.org/10.1016/j.technovation.2004.03.003

Hughes, M., Ireland, R. D. \& Morgan, R. E. (2007). Stimulating Dynamic Value: Social Capital and Business Incubation as Pathway to Competitive Success, Long Range Planning, 40, 154-177. https://doi.org/10.1016/j.lrp.2007.03.008

INE (2015a). Tasa de paro en España. Encuesta de Población Activa. Disponible en: http://www.ine.es/dyngs/INEbase/es/operacion.htm?c=Estadistica_C\&cid=1254736176918\&menu=ultiDatos\&idp=1254735976595

INE (2015b). Tasas de empresas desaparecidas. Demografía armonizada de empresas. Disponible en: http://www.ine. es/inebmenu/mnu_empresas.htm 
Lalkaka, R. et al (2002). Technology business incubators to help build an innovation-based economy. Journal of Change Managament. 3(2), 167-176. https://doi.org/10.1080/714042533

Lewis, D.A., (2001). Does technology incubation work? A critical review. Disponible en: /http://www.eda.gov/ImageCache/EDAPublic/documents/pdfdocs/lewis_5frutgers_5frept_2epdf/v1/lewis_5frutgers_5frept.pdfS.

Marimón, F. \& Alonso, J. M. (2005). Viveros de empresa en Cataluña. Tradicionales y especializados. Boletín económico del ICE, 2860, 31-46. Disponible en: http://repositori.udl.cat/bitstream/handle/10459.1/1802/BICE_2860_. pdf?sequence $=1$

Martínez, A. (1987). Gestión y planificación de los parques tecnológicos. Economía Industrial, 258, $103-111$.

McAdam, M. y McAdam, R. (2008). High tech start-ups in University Science Park incubators: the relationship between the start-up's lifecycle progression and use of the incubator's resources. Technovation, 28(5), $277-290$. https://doi.org/10.1016/j.technovation.2007.07.012

Marlow, S. y McAdam, M. (2011). Analysing the influence of gender upon high technology venturing within the context of business incubation. Entrepreneurship Theory and Practice, 36 (4), 655-676. https://doi.org/10.1111/ j.1540-6520.2010.00431.x

NBIA (1997). National Business Incubation Association publications. Disponible en: www. nbia.org

NBIA (2007). National Business Incubation Association publications. Disponible en: www. nbia.org

Perdomo Charry, G., Arias Pérez, J.E. \& Lozada Barahona, N.E. (2014). Business incubator research: a review and future directions. Pensamiento y Gestión, 37, 41-65. https://doi.org/10.14482/pege.37.7020

Peterson, J. (1985). Creating jobs by creating businesses: the role of business incubators. National Council for Urban Economic Development, Washington.

Rice, M. (2002). Co-production of business assistance in business incubators. An explanatory study. Journal of Business Venturing, 17, 163-187. https://doi.org/10.1016/s0883-9026(00)00055-0

Scaramuzzi, E. (2002). Incubators in developing Countries: Status and Development Perspectives. Washington, D.C.: The World Bank.

Scillitoe, J.L. \& Chakrabarti, A.K. (2010). The role of incubator interactions in assisting new ventures. Technovation, 30 (3), 155-167. https://doi.org/10.1016/j.technovation.2009.12.002

Smilor, R.W. \& Gill, M.D.J., (1986). The new business incubator: Linking talent, technology, capital, and know-how. Toronto: Lexington Books.

Thierstein, A. \& Wilhelm, B. (2001). Incubator, technology and innovation centres in Switzerland: Features and policy implications. Entrepreneurship and Regional Development, 13(4), 315-31. https://doi. org/10.1080/08985620110074469

Totterman, H. \& Sten, J. (2005). Start-ups. International Small Business Journal, 23 (5), 487-511. https://doi. org/10.1177/0266242605055909

UKBI (2007). What is business incubation? Disponible en: http:// www.ukbi.co.uk.

Uribe, J. \& De Pablo, J. (2009). Aproximación al modelo europeo de viveros de empresas. Estudios de casos. Boletín Económico del ICE, Ministerio de Industria, Turismo y Comercio, 2973, 41-48. Disponible en: http://www.revistasice.com/cachepdf/BICE_2973_41-47_A4788D5907107CB2218273DEDCB66C2E.pdf

Vaquero, A. \& Ferreiro, F. (2010a). Los viveros en Galicia: Un análisis de su funcionamiento. XII Congreso Hispano-Luso. Ourense.

Vaquero, A. \& Ferreiro, F. (2010b). El papel de los viveros de empresa en Galicia como agentes de promoción económica y generación de empleo. Santiago de Compostela: Xunta de Galicia. Consellería de Traballo e Benestar.

Vaquero, A. \& Ferreiro, F. (2011). Los viveros gallegos como instrumento de desarrollo local: Situación actual y líneas de mejora. Revista Galega de Economía, 20(1), 1-23.

Vaquero, A. \& Ferreiro, F. (2014). Experiencias regionales en viveros de empresas. Revista de Estudios Regionales. Universidades Públicas de Andalucía.

Velasco, B. (1995). Incubadoras de Empresas, Incubadoras de Negocios. Memorias VI Seminario Latinoamericano de Gestión Tecnológica, pp. 299-302. Santiago de Chile. 